\title{
Produção de conteúdo acessível para surdos na web: análise do canal de vídeos Ôxe
}

Accessible content production to deaf people on the web: analysis of the video channel Ôxe

La producción de contenidos accesibles a los sordos en la web: análisis del canal de videos Ôxe

DOI: $10.1590 / 1809-5844201829$

\section{Gabriela Lapa Teles Barbosa ${ }^{1}$}

https://orcid.org/0000-0001-6111-0017

\section{Karin Müller ${ }^{2}$}

http://orcid.org/0000-0002-1029-5282

${ }^{1}$ (Universidade do Estado da Bahia, Departamento de Ciências Humanas, Programa de Pós-Graduação em Educação, Cultura e Territórios Semiáridos. Juazeiro - BA, Brasil)

${ }^{2}$ (Universidade Metodista de São Paulo, Faculdade de Gestão e Serviços, Cursos de Marketing, Gestão de Recursos Humanos e Gestão da Qualidade. São Bernardo do Campo - SP, Brasil. Universidade Metodista de São Paulo, Escola Metodista de Educação Corporativa, Pós-Graduação em Gestão de Conteúdo em Comunicação - Jornalismo. São Bernardo do Campo - SP, Brasil)

\section{Resumo}

O artigo discute a produção de conteúdo acessível a surdos na web, por meio do estudo de caso do canal de vídeos Ôxe, localizado na plataforma YouTube. Descreve e analisa sua proposta e características para identificar como ele dialoga com o debate sobre acessibilidade, e quais inovações sua experiência agrega ao campo da Comunicação. Os dados foram coletados na página do canal no YouTube, considerando os vídeos publicados entre julho de 2015 e janeiro de 2016. Entre os resultados, destaca-se a necessidade de incentivar o aumento quantitativo e qualitativo de produtos comunicacionais acessíveis.

Palavras-chave: Libras. Acessibilidade. Gestão de conteúdo. Novas tecnologias. YouTube.

\begin{abstract}
The article discusses the production of content accessible to the deaf on the web, through the case study of the Ôxe video channel on the YouTube platform. Describes and analyses its proposal and characteristics to identify how it dialogues with the accessibility debate, and what innovations its experience adds to the field of Communication. The data were collected on the channel page on YouTube, considering the videos published between July 2015 and January 2016. Among the results, stands out the need to encourage the quantitative and qualitative increase of accessible communication products.
\end{abstract}

Keywords: Brazilian Sign Language. Accessibility. Content management. New technologies. YouTube. 


\section{Resumen}

El artículo discute la producción de contenido accesible a sordos en la web, a través del estudio de caso del canal de videos Ôxe, localizado en la plataforma YouTube. Describe y analiza su propuesta y características para identificar cómo él dialoga con el debate sobre accesibilidad, y cuáles innovaciones su experiencia agrega al campo de la Comunicación. Los datos fueron recogidos en la página del canal en YouTube, considerando los vídeos publicados entre julio de 2015 y enero de 2016. Entre los resultados, se destaca la necesidad de incentivar el aumento cuantitativo y cualitativo de productos comunicacionales accesibles.

Palabras clave: Libras. Accesibilidad. gestión de contenidos. Nuevas tecnologías. YouTube.

\section{Introdução}

O uso de Tecnologias de Informação e Comunicação (TICs) acessíveis a surdos é um tema que vem crescendo no Brasil, principalmente, a partir dos anos 2000, com o reconhecimento da Língua Brasileira de Sinais (Libras), por meio da Lei 10.436/2002 (BRASIL, 2002), e a criação da Lei de Inclusão da Pessoa Com Deficiência (PCD) 13.146/2015, a qual aborda, entre outros aspectos, o direito à informação, cultura e lazer em formato acessível (BRASIL, 2015).

Essas normativas chamaram a atenção para as particularidades linguísticas dos surdos, que, de acordo com o último censo demográfico do $\mathrm{IBGE}^{1}$, representam 7,6\% da população com deficiência no Brasil, o equivalente a mais de 3 milhões de pessoas (OLIVEIRA, 2012). Ambas as normativas fomentaram o debate sobre a importância da acessibilidade para proporcionar maior autonomia e inclusão desses sujeitos na sociedade.

A Lei 10.436/2002, por exemplo, estabelece que o poder público - incluindo empresas concessionárias de serviços públicos - apoie o uso e a difusão da Libras como meio de comunicação objetiva e de utilização corrente (BRASIL, 2002). O Decreto 5.626, de 22 de dezembro de 2005, que passou a regulamentar essa normativa, determinou a inclusão da Libras como disciplina obrigatória nos cursos de Fonoaudiologia e Formação de Professores para o Magistério Médio e Superior; e como disciplina optativa nos demais cursos, em todas as instituições de ensino do país, públicas e privadas. Concessionárias de serviços públicos e toda a administração pública também passaram a ter que disponibilizar atendimento no idioma com pelo menos $5 \%$ do quadro de servidores e funcionários capacitados para tal (BRASIL, 2005).

Na mesma linha, em 2014, a Agência Nacional do Cinema, por meio da instrução normativa $n^{0} 116$, instituiu a obrigatoriedade de recursos de legendagem, audiodescrição e Libras em todos os projetos de produção audiovisual financiados com recursos públicos federais geridos por ela, como forma de promover a acessibilidade (BRASIL, 2014).

1 Disponível em https://ww2.ibge.gov.br/home/estatistica/populacao/censo2010/caracteristicas_religiao_deficiencia/default_ caracteristicas_religiao_deficiencia.shtm. Acesso em: 20 nov. 2015 
Embora, numa perspectiva clínica, ou orgânica, a surdez seja definida como a redução da capacidade de percepção dos sons (RINALDI et al, 1997), ela também pode ser compreendida, além do âmbito da deficiência auditiva, como marca identitária de um grupo cultural específico. Nesse entendimento, os surdos "são pessoas que não se consideram deficientes, utilizam uma língua de sinais, valorizam sua história, arte e literatura, e propõem uma pedagogia própria para a educação das crianças surdas” (BISOL; VALENTINI, 2011, p.1). Segundo Sacks (1998), a língua de sinais é a forma natural de comunicação desses sujeitos, pois sua modalidade gesto-visual a torna acessível em comparação com as línguas orais, como o Português.

Criada na segunda metade do século XIX, a Libras só foi oficializada em 2002, a partir de quando os surdos brasileiros passaram a ter duas línguas oficiais, sendo a primeira a Libras, e a segunda, o Português (BRASIL, 2002; MONTEIRO, 2006; RAMOS, 2006; QUEIROZ; RÚBIO, 2014). As dificuldades de compreensão dessa segunda língua, pelas diferenças estruturais e de sentido que apresenta em relação à Libras, constituem uma barreira de acesso que, muitas vezes, não é percebida por produtores de sites e conteúdos digitais, como observam Goes e Gomes (2011). Segundo essas autoras, quando examinamos os recursos de acessibilidade existentes para surdos na rede mundial de computadores, temos na maioria das vezes, apenas vídeos com legendas explicativas em Português - o que não contempla a realidade deste grupo social, que utiliza o Português como segunda língua.

Elas apontam que isso acontece pelo senso comum de que os surdos não ouvem, mas conseguem ler e compreender textos escritos em Português, porque a leitura visual estaria relacionada a um sentido que lhes é funcional; e sugerem o uso de tradutores e janelas de Libras, além da produção de conteúdo nessa língua, para que os surdos possam ter acesso a uma diversidade maior de produtos comunicacionais para consumir, contribuindo mais efetivamente com a superação da barreira linguística para a sua inclusão efetiva na sociedade.

De olho nessa demanda, diversas TICs surgiram com a proposta de minimizar as barreiras comunicacionais em diferentes mídias, oferecendo ampliação de acesso dos surdos, por exemplo, ao cinema, à televisão e à Internet. Em 2013, surgiu a primeira emissora de televisão para surdos, a TV INES, fruto de uma parceria entre o Instituto Nacional de Educação dos Surdos (INES) e a Associação de Comunicação Educativa Roquette Pinto (ACERP). Com uma equipe formada por seis apresentadores surdos e cinco intérpretes de Libras, ela oferece programação de filmes, notícias, desenhos animados, esporte, cultura e tecnologia, que é distribuída por satélite a parabólicas, TVs a Cabo, Smart, celulares e tablets. Tudo é feito em Libras e traduzido para o Português com legendas (SIQUEIRA; SOUZA, 2016)

Alguns estudos, como o de Amorim et al (2010), apontam possibilidades de traduzir as legendas ocultas para Libras criando sinais em extensão animada GIF. Além disso, existem tradutores que podem ser usados em dispositivos móveis e totens de atendimento, 
como o ProDeaf, premiado internacionalmente 2 , e o HandTalk, considerado pela ONU, em 2013, como o melhor aplicativo de inclusão social do mundo 3 .

Inserir essas tecnologias na produção de conteúdos dos mais diversos gêneros é um desafio no campo da Comunicação, pois é preciso estar preparado não somente para transpor barreiras linguísticas, mas também atender às demandas do público surdo por informação de qualidade conectada com suas culturas e interesses,

permitindo aos surdos pertencer a um determinado grupo específico onde eles são capazes de iniciar a construção de fronteiras identificatórias com o outro, bem como, obter o reconhecimento social dos demais grupos, [pois] a constituição da identidade pelo surdo está relacionada à presença de uma língua que lhe dê a possibilidade de constituir-se como "sinalizante" que consiga estabelecer práticas discursivas e sociais (QUADROS; STUMPF, 2009, p.171).

Nesse sentido, nosso artigo analisa o canal Ôxe, localizado na plataforma YouTube, criado em 2015 por um grupo de jovens alagoanos com a proposta de produzir vídeos de humor acessíveis em Libras.

\section{O papel das novas tecnologias na inclusão de pessoas com deficiência}

A Lei 13.146/2015 representou um marco na busca pela inclusão social das pessoas com deficiência (PCD), ao dispor sobre a eliminação das barreiras de acesso aos direitos e garantias fundamentais para proporcionar a esses sujeitos o exercício pleno da cidadania.

No campo da Comunicação, tornou obrigatórios a acessibilidade nos produtos culturais e sítios da Internet, e o uso de tecnologias como legenda, audiodescrição e janela de Libras nos serviços de radiodifusão de som e imagem (BRASIL, 2015), fomentando o debate sobre a importância das TICs no processo de inclusão social.

O Estatuto da Pessoa com Deficiência define acessibilidade como "um direito que garante à pessoa com deficiência ou com mobilidade reduzida viver de forma independente e exercer seus direitos de cidadania e de participação social” (BRASIL, 2015, art.53), através da utilização segura e autônoma de espaços, mobiliários, equipamentos urbanos, edificações, transporte, informação e comunicação.

Essa autonomia no uso dos meios de comunicação compreende ter acesso a recursos tecnológicos adaptados às limitações motoras, visuais, auditivas e cognitivas dos usuários em meios tanto analógicos como digitais, a exemplo das impressoras e teclados em Braille, digitalizadores de voz, ampliadores de caracteres e leitores de texto (BRASIL, 2015).

2 Disponível em <https://www.facebook.com/prodeafLibras/info/?tab=page_info>. Acesso em: 15 nov. 2015.

3 Disponível em <http://g1.globo.com/al/alagoas/noticia/2013/02/aplicativo-alagoano-hand-talk-e-eleito-o-melhor-do-mundo-emconcurso.html>. Acesso em: 15 nov. 2015. 
Especificamente no meio digital, a acessibilidade abarca, conforme apontam Conforto e Santarosa (2002):

(1) a acessibilidade ao computador que engloba programas (software) de acesso incluindo diferenciados tipos de Ajudas Técnicas para uso genéricos de acesso aos computadores e periféricos (maior detalhamento ver em Hogetop e Santarosa (2001) ou que podem ser especialmente programados para o acesso a WEB; (2) a acessibilidade ao Navegador, os quais podem ser genéricos como o Microsoft Explorer e o Netscape Navigator. Contudo, existem navegadores específicos que oferecem facilidade de acesso a diferentes usuários como o navegador só de texto LYNX para cegos; (3) a acessibilidade ao planejamento de páginas web, que envolve várias dimensões como conteúdo, estrutura e formato. O elemento fundamental, neste caso, é a escolha da ferramenta de construção de páginas que possa oferecer maiores possibilidades de opções de acessibilidade (p.2).

Em uma perspectiva mais ampla, a acessibilidade não diz respeito somente à pessoa com deficiência física, motora ou cognitiva, mas a qualquer usuário cuja condição temporária ou permanente interfira no modo como ele utiliza a tecnologia: é o que orienta o Consórcio Mundial Para a Web (WC3), organização responsável pela acessibilidade na world wide web (BEZ; MONTARDO; PASSERINO, 2008). Trata-se de um consórcio em que organizações filiadas, profissionais e o público geral trabalham para desenvolver padrões como o HTML e CSS, gratuitos e abertos, com o objetivo de garantir a evolução da web (WC3, 2015).

Em 1997, a WC3 criou a Iniciativa para Acessibilidade na Web (WAI) com a missão de promover o acesso de pessoas com deficiência à Internet e passou a estudar a elaboração de recomendações para o uso de tecnologias adaptadas a diferentes necessidades especiais. Em 2015, o escritório brasileiro do Consórcio, atuante no país desde 2008, divulgou o primeiro fascículo da cartilha de acessibilidade na web: um documento de 47 páginas com recomendações iniciais, diretrizes e contextualização do tema (VENTURA, 2015).

As primeiras recomendações concentraram-se em princípios básicos do design universal, como uso simples e intuitivo, de forma que qualquer usuário, independentemente do nível de experiência, possa desfrutar da web sem prejuízo; mínimo de esforço físico, para que o uso seja eficiente e confortável com um mínimo de fadiga; informação perceptível, fácil de ser encontrada; e flexibilidade de uso para atender a uma maior gama de indivíduos, preferências e habilidades (WC3, 2015).

Para Montardo e Passerino (2007), incluir efetivamente as pessoas com deficiência implica em criar condições para que elas possam satisfazer suas necessidades de desenvolvimento, qualidade de vida, equidade e oportunidade de direitos. As referidas autoras defendem que a inclusão digital é uma faceta da inclusão social; ela é "o direito 
de acesso ao mundo digital para o desenvolvimento intelectual (educação, geração de conhecimento, participação e criação) e para o desenvolvimento de capacidade técnica e operacional” (p.3).

Nesse sentido, as TICs são os meios pelos quais esses sujeitos podem consumir e produzir o conhecimento necessário à superação das limitações para sua participação ativa na sociedade, possibilitando não só a minimização das barreiras existentes, mas também contribuindo com a desconstrução de preconceitos e estereótipos (WARSCHAUER, 2006). Segundo Albuquerque Jr. (1999), o estereótipo é uma caracterização "grosseira e indiscriminada do grupo estranho, em que as multiplicidades e diferenças individuais são apagadas em nome de semelhanças superficiais” (p.30).

Porém, para atender às demandas desses usuários, garantir o acesso às tecnologias não é suficiente. As TICs precisam oferecer pluralidade de conteúdos que dialoguem com as diferentes realidades culturais, políticas e econômicas dos atores sociais, para que eles possam efetivamente transformá-las, como Montardo e Passerino (2007) sugerem.

Goes e Gomes (2011) chamam a atenção para o fato de que todo o processo de significação de mundo e desenvolvimento de cognição do surdo acontece visualmente através dos sinais. A escrita, por determinação da legislação brasileira, é aprendida em Português, como um segundo idioma, mas as correspondências entre os dois são limitadas na literalidade, principalmente por se tratarem de Línguas de modalidades diferentes (GOES; GOMES, 2011).

Uma vez que aprendem a ler e escrever o Português sem o conhecimento fonológico da Língua, esses surdos são considerados leitores não alfabetizados (FERNANDES, 2006).

Quando o surdo acessa a Internet, sua experiência de navegação é permeada por essas formas visuais de contato e significação da informação e conhecimento. [...] Quando nos referimos ao internauta surdo, usuários da LIBRAS, é preciso lembrar que ele é um indivíduo bilíngue, cujo domínio da Língua Portuguesa se dá como leitura em segunda língua. Dependendo de seu nível de proficiência, a leitura em Língua Portuguesa poderá se apresentar de maneira fragmentada e limitada, comprometendo a possibilidade de leitura imersiva (GOES; GOMES, 2011, p.7-11).

Essas autoras sugerem o desenvolvimento de conteúdos em Libras e o uso de tradutores aperfeiçoados como solução mais adequada à promoção da acessibilidade de comunicação para surdos, ainda que, assim como ocorre em qualquer processo de tradução entre idiomas, não seja possível transcrever, sempre, o conteúdo com exata correspondência.

No presente artigo, buscamos responder à seguinte questão: como o canal Ôxe dialoga com o debate sobre acessibilidade e inclusão social dos surdos e que inovações traz nesse sentido para o campo da Comunicação? 


\section{Canal Ôxe: uma experiência de comunicação acessível}

O canal Ôxe foi criado em 2015, por um grupo de jovens maceioenses que tinham como proposta produzir vídeos de humor acessíveis em Libras. Buscando pelos termos humor em Libras no YouTube, plataforma na qual o canal está disponível, não encontramos, à época ${ }^{4}$, iniciativas semelhantes, o que despertou nossa curiosidade para as contribuições que esse canal poderia trazer ao campo da Comunicação, especialmente no que diz respeito à discussão sobre acessibilidade e inclusão social de surdos.

Partimos da premissa de que esse público é quantitativamente expressivo no Brasil e possui demandas comunicacionais específicas, como o uso da Libras e as dificuldades de compreensão do Português enquanto segunda língua, que precisam ser consideradas pelos produtores de conteúdo para tornar seus produtos acessíveis. Essa necessidade é ainda mais relevante tendo em vista as várias normativas, como as já mencionadas leis 10.436/2002, 13.146/2015 e a instrução normativa $\mathrm{n}^{\circ} 116$ da Ancine, que asseguram aos surdos o direito de acesso à cultura e comunicação em formato acessível.

Metodologicamente, optamos pelo estudo de caso, com descrição e análise da proposta e características do canal, para identificar como ele dialoga com o debate sobre acessibilidade, e quais inovações sua experiência agrega ao campo da Comunicação. Os dados foram coletados em reportagens sobre o Ôxe publicadas na Internet e na página do canal no YouTube, considerando os vídeos publicados entre julho de 2015 e janeiro de 2016.

Quanto à proposta, identificamos os seguintes aspectos:

1 - O Ôxe lançou a ideia de oferecer vídeos de humor acessíveis aos surdos na web com o objetivo de incluir esses sujeitos entre o seu público e incentivar outros canais a produzirem conteúdos com acessibilidade, conforme expresso na descrição do primeiro vídeo acessível.

Estamos lançando esse novo material e os nossos vídeos anteriores com a ideia de levar a nossa mensagem para todos os públicos, agora com o projeto "HUMOR PARA TODOS” visa deixar mais acessível para a comunidade surda, fiquem ligados no \#CANALOXE, lançamos com essa visão de estimular a produção de conteúdo com acessibilidade a outros canais (MATUTO..., 2015).

2 - O canal adotou a janela de Libras como tecnologia acessível, utilizando essa ferramenta em dez dos doze vídeos publicados entre julho de 2015 e janeiro de 2016. Trata-se de um recurso no qual o conteúdo de cada vídeo é traduzido para Libras por um intérprete que fica no canto da tela.

$4 \quad$ Busca realizada em 10 out. 2015 
Tudo começou quando já tínhamos lançado dois vídeos. O Abner [Antônio, 23, diretor de arte] nos comunicou sobre essa ideia de implantar Libras em nossos materiais. Nós todos apoiamos a ideia na hora. A partir daí, a gente parou a produção de novos vídeos por duas semanas para estudar qual seria a melhor estratégia para criar esse conteúdo (ALVES, 2015).

3 - A proposta de acessibilidade era destacada no título de cada vídeo por meio da hashtag" \#LIBRAS "HUMOR PARA TODOS”, com o propósito de chamar a atenção dos surdos que frequentassem o canal. Com isso, os criadores pretendiam incentivar o público a interagir e sugerir conteúdos.

Nós esperamos que a comunidade surda se identifique com o que lançamos e que compartilhem conosco as suas histórias engraçadas, que nos ajudem a gerar conteúdo. Queremos que isso sirva de incentivo para que outros canais também lancem seus conteúdos com acessibilidade, sem aquelas barreiras que insistimos em criar (ALVES, 2015).

Em relação às características do canal, percebemos que:

1 - Buscou produzir vídeos humorísticos com base em temas diferentes relacionados ao cotidiano, como andar de ônibus, conseguir um emprego, votar e fofocar.

2 - Destacou a proposta de acessibilidade nos títulos dos vídeos, usando letras maiúsculas e a hashtag \#LIBRAS “HUMOR PARA TODOS”.

3 - Não manteve periodicidade na atualização dos vídeos, embora contasse na página do canal no YouTube que eles seriam publicados semanalmente, sendo que dos 12 publicados no período estudado, seis foram lançados com sete dias de intervalo, um com oito dias, um com dez dias, um com 14 dias, um com 18 e um com 19 dias.

4 - Obteve 851 inscritos (pessoas que se cadastram no canal para receber conteúdo atualizado) e um total de visualizações superior a 18 mil.

5 Hashtag é o símbolo \# seguido de uma palavra ou frase. Essa tecnologia permite aos usuários o encontro em torno de temáticas comuns e por isso vem sendo usada de forma sistemática como uma nova arma de protesto e ativismo online (SILVA, 2012). 
Tabela 1 - Relação de vídeos produzidos pelo Canal Ôxe, com data de publicação e quantidade de visualizações (un.)

\begin{tabular}{lcc} 
Nome do vídeo & Data de publicação & Visualizações (un.) \\
\hline Minha última cana & $04 / 07 / 2015$ & 2.685 \\
Cacete materno & $11 / 07 / 2015$ & 1.738 \\
Resenhas de buzão & $18 / 07 / 2015$ & 2.755 \\
Judite Bola Gato & $05 / 08 / 2015$ & 1.787 \\
Matuto na cidade grande & $15 / 08 / 2015$ & 1.916 \\
Meu primeiro atentado & $22 / 08 / 2015$ & 1.259 \\
Snapchat complicando a minha vida & $29 / 08 / 2015$ & 796 \\
Fofoqueiras de plantão & $05 / 09 / 2015$ & 2.082 \\
Eu amo meu emprego & $19 / 09 / 2015$ & 437 \\
Benedito Bentes & $26 / 09 / 2015$ & 1.113 \\
Quem mandou votar na Dilma & $03 / 10 / 2015$ & 833 \\
Coisas constrangedoras & $22 / 10 / 2015$ & 975 \\
\hline Total & 12 & 18.376 \\
\hline
\end{tabular}

Fonte: YouTube. Elaborado pelas autoras.

A partir dos dados apresentados, concluímos que, entre as potencialidades percebidas na experiência do Ôxe, o canal inovou ao propor acessibilidade adotando a janela de Libras como recurso, ao invés das legendas em Português, como mencionamos que acontece comumente entre os desenvolvedores de sites e conteúdos digitais. Sua experiência também demonstrou a necessidade de planejamento na criação dos conteúdos para serem traduzidos em Libras, em função do tempo demandado para tradução e inserção da janela, e chamou a atenção para a possibilidade de promover inclusão dos surdos por meio do incentivo para que eles sugerissem temas para os vídeos que fossem dos seus interesses.

Entre as limitações identificadas, destacamos a falta de periodicidade regular nas publicações, perceptível na Tabela 1, e a ausência de um vídeo, com tradução, que explicitasse o convite aos surdos para que enviassem sugestões de temas, pois essa possibilidade só foi mencionada em Português, na descrição do primeiro vídeo postado com janela de Libras, o que não condiz totalmente com a proposta de acessibilidade.

\section{Considerações Finais}

As discussões em torno da acessibilidade e dos direitos da pessoa com deficiência vêm ganhando corpo em todo o mundo, mas especialmente no cenário nacional, nos últimos anos, com a aprovação da Lei 10.436 de 24 de abril de 2002, que reconheceu a Libras como o idioma dos surdos e o segundo oficial do Brasil; e da Lei 13.146, de 06 de julho de 2015, conhecida como o Estatuto da Pessoa com Deficiência, que reafirma a acessibilidade 
como um direito do povo e a eliminação de barreiras, entre outros aspectos, à informação e comunicação, como um dever do Estado.

Estes marcos legais abriram caminho para que as pessoas com deficiência ampliassem sua participação na sociedade, facilitando o acesso à educação, emprego e serviços como o uso das novas Tecnologias de Informação e Comunicação (TICs). Muitas discussões vêm sendo feitas, desde então, destacando o potencial da tecnologia tanto no desenvolvimento individual do sujeito, proporcionando a superação de limites físicos e cognitivos, como no crescimento da sociedade enquanto organismo coletivo, na medida em que as TICs permitem ao usuário aprender, interagir e transformar-se, transformando também o outro em um movimento contínuo e infinito.

O resultado disso é a criação de uma série de ferramentas, como tradutores e aplicativos, que facilitam a interação e o acesso dos PCD à vida social e chamam a atenção para a necessidade de oferecer serviços diversos e adequados aos interesses de consumo desta parcela expressiva da população. A produção de conteúdo é, neste contexto, um desafio no campo das Ciências da Comunicação, pois torna-se cada vez mais urgente suprir a demanda do público PCD, não só no quesito usabilidade, mas principalmente no processo produtivo da informação, que precisa considerar gostos e perfis destes consumidores exigentes, não mais atendo-se apenas à superação da limitação provocada pela deficiência.

Para ilustrar a discussão, esta pesquisa analisou o canal Ôxe, criado por um grupo de alagoanos em 2015, na plataforma YouTube, com o objetivo de veicular piadas e vídeos de humor, tendo adotado a janela de Libras como ferramenta de acessibilidade para os surdos. O canal Ôxe apresentou uma proposta de promoção da acessibilidade para surdos na web que trouxe elementos interessantes para o campo da Comunicação, como o incentivo à participação desses sujeitos no processo de criação dos conteúdos, por meio do envio de sugestões de temas que refletissem seus interesses. A adoção da janela de Libras como recurso acessível, em substituição às tradicionais legendas em Português, foi outra inovação que, ao nosso ver, contribui com o reconhecimento das demandas comunicacionais desse público.

Porém, identificamos, também, algumas limitações, como a ausência de periodicidade regular nas publicações, a qual resultou em intervalos muito diferentes de tempo entre a disponibilização dos vídeos no canal, divergindo da proposta de publicação semanal de conteúdo, anunciada na página do Ôxe no YouTube.

Outra limitação observada foi a ausência de um formato acessível para o convite feito aos surdos de participarem do processo de criação dos conteúdos do canal, enviando sugestões de temas. O convite foi realizado por meio de texto quando o primeiro vídeo com janela de Libras foi publicado, sem haver tradução dessa mensagem para a língua de sinais. Como a proposta do canal foi de oferecer conteúdo acessível e convidar os surdos a se identificar e participar da sua construção, entendemos que teria sido mais apropriado disponibilizar o convite em Libras. 
De maneira geral, percebemos que a proposta do Canal refletiu as discussões sobre a importância de disponibilização de recursos acessíveis para os surdos, bem como de ampliação de sua participação na sociedade tendo suas necessidades e demandas comunicacionais reconhecidas e consideradas no processo de produção de informações.

Frente ao exposto, acreditamos que a experiência do canal Ôxe refletiu um tema atual e importante para o campo da Comunicação, que pode ser explorado por outros produtores de conteúdos digitais para aumentar a oferta de produtos comunicacionais acessíveis e de qualidade aos surdos.

\section{Referências}

ALBUQUerQue JR., D. M. A invenção do Nordeste. Recife/São Paulo: Fundação Joaquim Nabuco e Editora Cortez, 1999.

ALVES, M. Alagoanos lançam vídeo de humor na internet com tradução em libras: depoimento [15 ago., 2015]. Maceió: Portal G1 Alagoas. Entrevista concedida a Derek Gustavo.

AMORIM, M. L. C.; ASSAD, R.; LÓSCIO, B. F.; FERRAZ, F. S.; MEIRA, S. RybenáTV: solução para acessibilidade de surdos para TV Digital. In: XVI Simpósio Brasileiro de Sistemas Multimídia e Web, 2010, Belo Horizonte. Tópicos em Sistemas Colaborativos, Interativos, Multimídia, Web e Banco de Dados. Belo Horizonte: Sociedade Brasileira de Computação, 2010. v.1. p.1-5.

BEZ, M. R.; MONTARDO, S. P.; PASSERINO, L. M. Acessibilidade digital em blogs: limites e possibilidades para socialização online de pessoas com necessidades especiais. Revista Eletrônica Internacional de Economia Política da Informação, da Comunicação e da Cultura, v.10, n. 1, jan-abr 2008.

BISOL, C. A.; VALENTINI, C. B. Surdez e deficiência auditiva - qual a diferença?. Objeto de Aprendizagem Incluir - UCS/FAPERGS, 2011.

BRASIL. Agência Nacional do Cinema. Instrução normativa no 116 de 18 de dezembro de 2014. Dispõe sobre as normas gerais e critérios básicos de acessibilidade a serem observados por projetos audiovisuais financiados com recursos públicos federais geridos pela ANCINE. Disponível em: <http://www.ancine.gov. br/legislacao/instrucoes-normativas-consolidadas/instru-o-normativa-n-116-de-18-de-dezembro-de-2014>. Acessado em: 19 nov. 2015.

BRASIL. Decreto ${ }^{0}$ 5.626, de 22 de dezembro de 2005. Regulamenta a Lei no 10.436, de 24 de abril de 2002. Disponível em: http://www.planalto.gov.br/ccivil_03/_ato2004-2006/2005/decreto/d5626.htm. Acessado em: 06 nov. 2015.

Lei no 10.436, de 24 de abril de 2002. Dispõe sobre a Língua Brasileira de Sinais - Libras e dá outras providências. Disponível em <http://www.planalto.gov.br/ccivil_03/leis/2002/L10436.htm>. Acessado em: 06 nov. 2015.

Lei $\mathbf{n}^{\circ}$ 13.146, de 03 de julho de 2015. Institui a Lei brasileira de inclusão da pessoa com deficiência (Estatuto da Pessoa com Deficiência). Disponível em: http://www.planalto.gov.br/ccivil_03/_ato20152018/2015/lei/113146.htm. Acessado em: 06 nov. 2015.

CONFORTO, D.; SANTAROSA, L. M. C. Acessibilidade à Web: Internet para Todos. Revista de Informática na Educação: Teoria, Prática. Porto Alegre, v.5, nº 2, nov/2002. p.87-102.

FERNANDES, S. F. Práticas de educação bilíngue no letramento para surdos. Curitiba: SEED, 2006. 
GOES, A. R. S.; GOMES, R. C. E-acessibilidade para surdos. Revista Brasileira de Tradução Visual. Recife, v.7, n.7, 2011.

MATUTO... YouTube, 15 aug. 2015. Disponível em: <https://www.youtube.com/watch?v=nbbUTvZtqpg>. Acessado em: 05 nov. 2015.

MONTARDO, S. P.; PASSERINO, L. M. Inclusão social via acessibilidade digital: proposta de inclusão digital para pessoas com necessidades especiais. Revista da Associação Nacional dos Programas de PósGraduação em Comunicação. Belo Horizonte, v.8, 2007. Disponível em: <http://compos.org.br/seer/index. php/e-compos/article/view/144/145>. Acessado em: 01 jan. 2016.

MONTEIRO, M. S. História dos movimentos dos surdos e o reconhecimento da Libras no Brasil. Educação Temática Digital, Campinas, v.7, n.2, p.292-302, jun. 2006.

OLIVEIRA, M. L. B. Cartilha do censo 2010 - pessoas com deficiência. Brasília: SDH-PR/SNPD, 2012.

QUADROS, R. M. de. STUMPF, M. R. O primeiro curso de graduação em letras língua brasileira de sinais: educação à distância. Revista Educação Temática Digital, Campinas, v.10, n.2, p.169-185, jun. 2009.

QUEIROZ, L. S.; RÚBIO, J. A. S. A aquisição da linguagem e a interação social: a LIBRAS como formadora da identidade do surdo. Revista Eletrônica Saberes da Educação, São Roque, v.5, n.1. 2014. Disponível em: http://www.facsaoroque.br/novo/publicacoes/publi_atual_2014.html. Acessado em: 07 nov. 2015.

RAMOS, C. R. LIBRAS: A língua de Sinais dos Surdos brasileiros, 2006. Disponível em: < http://www. editora-arara-azul.com.br/pdf/artigo2.pdf>. Acessado em: 07 nov. 2015.

RINALDI, G. et al (Org.). Educação especial deficiência auditiva. Vol.I, série Atualidades Pedagógicas, n.04, Brasília: SEESP, 1997.

SACKS, O. Vendo vozes: uma viagem ao mundo dos surdos. São Paulo: Companhia das Letras, 1998.

SILVA, R. S. Twitter e ciberativismo: o movimento social da hashtag “\#ForaMicarla” em Natal-RN. 2012. 142f. Dissertação (Mestrado em Antropologia Social) - Centro de Ciências Humanas, Letras e Artes, Universidade Federal do Rio Grande do Norte, Natal. 2012.

SIQUEIRA, J. M.; SOUZA, J. B. de. Jornalismo e acessibilidade: TV INES, primeira webtv acessível do Brasil. In: CONGRESSO DAS CIÊNCIAS DA COMUNICAÇÃO NA REGIÃO NORDESTE. Caruaru, 7 a 9 jul. 2016. Anais.... Disponível em: http://www.portalintercom.org.br/anais/nordeste2016/resumos/R52-14601.pdf. Acessado em: 10 ago. 2016.

VENTURA, L. A. S. Cartilha de acessibilidade na web. Blog Vencer Limites/O Estado de S. Paulo. 14/04/2015. Disponível em: : http://brasil.estadao.com.br/blogs/vencer-limites/cartilha-de-acessibilidade-naweb/. Acessado em: 05 jan. 2016.

WARSCHAUER, M. Tecnologia e inclusão social: a exclusão digital em debate. São Paulo: Senac São Paulo, 2006.

WORLD WIDE WEB Consortium Brasil (WC3). Cartilha Acessibilidade na WEB, 2015. Disponível em: http://www.w3c.br/pub/Materiais/PublicacoesW3C/cartilha-w3cbr-acessibilidade-web-fasciculo-I.html. Acessado em: 05 jan. 2016. 


\section{Gabriela Lapa Teles Barbosa}

Mestranda do Programa de Pós-Graduação em Educação, Cultura e Territórios Semiáridos da Universidade do Estado da Bahia (PPGESA/UNEB). Especialista em Gestão de Conteúdo em Comunicação pela Universidade Metodista de São Paulo. Bacharel em Comunicação Social - habilitação Jornalismo pela Universidade Federal de Alagoas. Atua como jornalista no Instituto Federal de Educação, Ciência e Tecnologia do Sertão Pernambucano. E-mail: gabriela.lapa@hotmail.com.

\section{Karin Müller}

Doutora e Mestre em Comunicação Social pela Universidade Metodista de São Paulo. Graduada em Comunicação Mercadológica pela Universidade Metodista de São Paulo. É coordenadora do curso de Pós-Graduação em Gestão de Conteúdo em Comunicação na Universidade Metodista de São Paulo. E-mail: karinkm@gmail.com.

Recebido em: 25.06.2016

Aceito em: 06.02.2018 